\title{
Winners and losers in merger mania
}

In the wake of this summer's flood of mergers involving biotechnology firms (see Table 1), industry insiders and Wall Street analysts say not all of these highly publicized deals will succeed. A clash of corporate cultures, inadequate synthesis of the firms' product lines, and internal pressures can conspire to turn a stockboosting deal into a disaster if corporate executives haven't done their homework. In some cases, a merger may be worse than a failure.

Board members of 12-year-old ImmuLogic (Waltham, MA), for example, called it quits this summer and returned $\$ 40$ million to shareholders after the firm's allergy vaccines failed to impress federal regulators. Although individual investors and mutual fund managers have become wary of smalland mid-cap biotech stocks, ImmuLogic turned down a potential suitor because the offer "lacked specificity, contained contingencies, and was not superior to the plan of liquidation," according to a company statement.

The history of AxyS Pharmaceuticals supports this kind of thinking. In November 1997, shares of Sequana Therapeutics (San Diego, CA) surged 25\% when it announced plans for a merger with Arris Pharmaceutical (South San Francisco, CA). The new company, AxyS Pharmaceuticals, kept its Bay Area headquarters, and executives said that the combination of Sequana's gene-hunting research and Arris' library of drug components and combinatorial chemistry would be a winning match (Nat. Biotechnol. 15, 1326).

But less than a year later, AxyS announced a \$13.2 million second-quarter loss and with it plans to shut down the former Sequana facility and lay off 85 of its 120 employees. In early October 1999, AxyS was trading between $\$ 3$ and $\$ 4$ a share, compared to the \$11-12 a share at the time of the initial deal. "The merger of two money-losing organizations is only going to compound the problem," says Viren Mehta, an analyst with Mehta and Associates. "That was the Sequana and AxyS story."

AxyS CEO John Walker, who now questions the long-term viability of the partnership, says there are several lessons he learned from the deal-the first being that Arris simply paid too much money. Sequana's market capitalization was $\$ 100$ million when Arris began courting it in mid-1997, but by the time of the deal, it was closer to $\$ 140$ million. The final offer was for $\$ 166$ million. "We should have been more patient," he says. "We probably could have waited for a downturn in the market for a better price."

Eric Niiler is a freelance science writer working in San Diego, CA.

\section{Table 1. Recent M\&A activity involving biotechnology companies.}

Oct DuPont (Wilmington, DE) announced the purchase of CombiChem (San Diego, CA) for $\$ 95$ million in cash. CombiChem uses computer modeling to predict the success of drug compounds and will become part of a DuPont's growing pharmaceutical division.

Oct Medlmmune (Gaithersburg, MD) announced acquisition of BioScience (W. Conshohocken, $\mathrm{PA}$ ) for approximately $\$ 440$ million. Medlmmune develops products in such areas as infectious diseases and transplant medicine; Bioscience is focused on AIDS and cancer.

Aug Merck paid $\$ 87$ million for Sibia Neurosciences (San Diego, CA), a Salk Institute spinoff with its treatments for Alzheimer's and Parkinson's disease in clinical trials.

Aug Cypros (Carlsbad, CA), a developer of drugs to treat ischemic disorders, merged with RiboGene (Hayward, CA), which is focusing on infectious diseases and treatments for wound care.

Aug Purdue Pharma (Norwalk, CT), which specializes in products for pain management, took over CoCensys (Irvine, CA), which is developing neurological and psychiatric disorder treatments.

July Johnson \& Johnson (New Brunswick, NJ) bought Centocor (Malvern, PA) for $\$ 4.9$ billion

July Drug-screening concern OSI (Uniondale, NY) acquired Cadus (Tarrytown, NY) for $\$ 1.5$ million.

June Abbott Laboratories (Abbott Park, IL) announced it would pay $\$ 7.3$ billion for Alza Corp (Palo Alto, CA), a developer of oncology and urology therapeutics as well as specialty drug delivery devices. Alza had bought its neighbor Sequus and its AIDS-related Kaposi's sarcoma treatment, Doxil, in late 1998.
Mehta says money isn't the only reason why mergers fail; often the dealmakers don't make it clear who's in charge in the boardroom and in the laboratory.

Indeed, AxyS's Walker says researchers and executives at the two firms had different approaches to drug development: Arris was looking for a vertically integrated approach from research to marketable products, while Sequana believed it should continue to hunt for disease-causing genes, which is expensive and time-consuming. "Their scientists wanted to expand science horizontally, we wanted applications that we could use for specific targets for drugs," he says. "The program was really not progressing."

Despite the potential problems, a merger between two fiercely independent firms can be fruitful, at least for the winner. Mehta points to the acquisition of Cadus by OSI in mid-July. Cadus' troubles began with a patent suit in 1996 by rival Sibia that kept it from using its core technology for genomics screening. It also lost $\$ 18$ million in damages and a collaborative deal with BristolMyers Squibb.

In July, Cadus sold its drug discovery assets (and employees) to OSI for only $\$ 1.5$ million. Overnight, OSI became a $\$ 130$ million firm with 220 employees. OSI's CEO Colin Goddard says he gained an important line of preclinical G-protein coupled receptors, core yeast technology, and, perhaps most importantly, talented researchers from Cadus. (Cadus's chief scientific officer remains on staff.) OSI developed a business plan within one month of the acquisition.

"There are no true mergers. There has to be one company that takes charge," says Goddard. "From the beginning, the situation at the top has to be clear. Biotech is entrepreneurial business, and entrepreneurs by their nature aren't easily changed."

Eric Niiler

\section{Pharmaceutical companies could also face trouble}

In the world of mergers, it's not always the small- or medium-size biotechs that face trouble. Internal pressures at large pharmaceutical companies to acquire certain product lines, even if it's not in the company's best interest, may lead to a failure, according to Charles Engelberg, an analyst at AmeriCal Securities in San Francisco. "Big pharma is no better than a portfolio manager in picking out biotech winners and distinguishing them from losers," he says. "Sometimes they do a deal based on internal needs and it turns out to be garbage."

Engelberg says he questions the long-term viability of the Johnson \& Johnson/Centocor merger (Nat. Biotechnol. 17, 844). He says the pharmaceutical firm is trying to regain market share of its struggling coronary stent business by acquiring a bundle of cardiovascular drugs and products. Engleberg doesn't believe the products acquired from Centocor will be profitable. "Here J\&J is driven by their own ineptitude. . .to buy Centocor and we don't think its going to work," he says. "We don't think it makes any sense." 